\title{
Fonološki opis govora Ložnice pri Žalcu (SLA 324)
}

\author{
Tjaša Jakop
}

IZVLEČEK: Krajevni govor Ložnice pri Žalcu (Slovenski lingvistični atlas, točka št. 324) spada $v$ štajersko narečno skupino, natančneje $v$ srednjesavinjsko narečje. Živahna preteklost kraja in njegova lega ob glavni prometnici Celje-Ljubljana je vplivala (in še vedno vpliva) na precej hiter razvoj govora in medsebojna jezikovna prepletanja, zato prihaja do raznih nepredvidljivih dvojnic za istovrstne jezikovne pojave. Tudi dolgi samoglasniški sistem je zaradi številnih položajnih in prostih različic precej zapleten.

ABSTRACT: The local speech of Ložnica pri Žalcu (Slovenian Linguistic Atlas, point 324) belongs to the Štajersko dialect group, or, more exactly, to the dialect of the Middle Savinja Valley. The vivid past of this settlement as well as its position near the major road connection between Celje and Ljubljana has influenced the relatively fast development of this speech as well as linguistic interaction resulting in various unpredictable doublets for linguistic phenomena of the same kind. Because of the numerous positional and free variants the system of long vowels is rather complicated as well.

\section{UVOD}

0.1 Naselje Ložnica leži kilometer in pol severno od Žalca. Ime je dobila po potoku, ki teče skozi vas. Sami prebivalci izgovarjajo ime vasi na več načinov (Lož'nicalLž́nica/L'žical'Žica in na Lož́nic/na Lózici), sami sebe pa imenujejo Ložnóča:n (I ed. in mn., oblika za ž. sp. je Ložno'ča: $n k a$, prid. pa lož'niški).

To je dokaj urbanizirano gručasto naselje v osrčju Spodnje Savinjske doline (na prehodu iz ravnine Spodnje Savinjske doline v Ložniško gričevje). Meri $2,4 \mathrm{~km}^{2}$ in ima 444 prebivalcev. Zaselka Spodnja in Zgornja Ložnica sta na obeh bregovih regulirane rečice Ložnica (omenjene že leta 1262), najnovejši del naselja pa je nastal na vzpetinici Škafarjev hrib (266 m). Spada v lokalno skupnost in upravno enoto Žalec.

0.2 Srednjesavinjski govori so na splošno malo raziskani in o njih ni na razpolago ravno veliko literature. ${ }^{1}$ Tudi v Slovanskem lingvističnem atlasu (OLA)

1 Tine Logar, Štajerska narečja, JiS 13 (1968), str. 171-175; Zinka Zorko, Štajerska narečja, Enciklopedija Slovenije 13, Ljubljana: Mladinska knjiga, 1999, str. 131-133. 
- srednjesavinjski govor ni predstavljen. Ložniški govor je prvi opisal Viljem Kralj v - svoji diplomski nalogi iz leta 1961 in ga naslednje leto zapisal še po vprašalnici za N SLA. Primerjava njegovih zapisov s sedanjimi kaže na precejšen razvoj govora v - naglasnih paradigmah, $v$ kratkem vokalizmu, kvantitetnih razmerjih in samoglasniških kvalitetah).

Medtem ko ima npr. V. Kralj (1961) vse dolge $a$-je zapisane kot zaokrožene, danes labializacije $a$-ja ni ali pa je (le v posameznih primerih) zelo šibka, zato sem jo redko zabeležila. Kralj ima za ozka sredinska samoglasnika zapisana le $\dot{e}$ : in $\dot{o}$ :, sama pa zanju slišim tudi malo manj ozki prosti različici (é:/e: oz. $\dot{o}: / o$ :).V primerih kratkega naglašenega $i$ ima Kralj (1962) še polglasnik ('nət, 'təč, 'məš, 'rət, 'sət, 'zət), medtem ko sedanje stanje izkazuje kratek $i$, ki celo teži k podaljšanju ('bik, 'miš, 'nit, 'rit, 'sit, 'tič). Izvorno kratki u je pri Kralju (1962) še kratek (k'rux), sedaj pa zanj slišimo tudi že dolgi $u\left(k^{\prime} r u: x\right)$, saj govor teži $\mathrm{k}$ daljšanju zadnjih ali edinih zlogov (npr. 'die:š, k'me:t, 'kuo:š, 'pie:s). Za dolgi cirkumflektirani ə in novoakutirani o v nezadnjih besednih zlogih ima Kralj (1962) $e$-jevski refleks ('lè:n, 'vé:s), danes pa (zlasti pri mlajših govorcih) prevladuje $a$-jevski refleks ('la:n, 'va:s). Kralj (1961) ima zapisanih tudi še nekaj starejših oblik za O ed. ž. sp. (s kost'jo:j, s kərv'jo:j, $z$ noč́jo:j), ki se ne uporabljajo več.

\section{INVENTAR}

$1.1 \quad$ SAMOGLASNIKI

1.1.1 Dolgi naglašeni samoglasniki i: u:
è:/ẹ:
o:/ọ:

[e:] [o:]

ie: uno:

a:/å:

1.1.2 Kratki naglašeni samoglasniki

i

u

e $\partial 0$ 
1.1.3 Kratki nenaglašeni samoglasniki

i u

$\partial$

[o]

e $\quad \mathrm{o}$

a

1.1.3.1 Silabemi so tudi $/ 1 /, / \mathrm{m} /, / \mathrm{n} /$ in $[\mathrm{n}]$.

1.2 SOGLASNIKI

1.2.1 Zvočniki

$[\mathrm{u}] \mathrm{m}$

$\mathrm{V}$

$1 \mathrm{r} n$

j

1.2.2 Nezvočniki

$\mathrm{p} \quad \mathrm{b} \quad \mathrm{f}$

$t \quad d$

$\begin{array}{llll}c & & s & Z\end{array}$

č $\quad \check{s} \quad \check{z}$

$\mathrm{k} \mathrm{g} \quad \mathrm{x}$

1.3 NAGLAS

1.3.1 Naglas ni vezan na določeno mesto $\mathrm{v}$ besedi.

1.3.2 Naglašeni samoglasniki so lahko dolgi in kratki, nenaglašeni samoglasniki pa so lahko samo kratki.

1.3.3 Kratko naglašeni so lahko tudi nezadnji zlogi, in sicer zaradi krajšanja visokih, izvorno dolgih samoglasnikov ('zima, 'muxa) in mladega naglasnega umika s končnih kračin nanju ('cogan).

1.3.4 Govor ne pozna tonemskega naglaševanja. Naglas je jakosten, meje med dolgo in kratko naglašenimi samoglasniki pa so včasih nejasne.

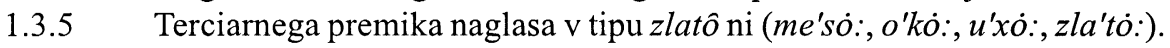

1.3.6 Govor ima tako dva naglasa $(' V:, ' V)$ in nenaglašeno kračino $(V)$. 


\section{DISTRIBUCIJA}

\section{$2.1 \quad$ SAMOGLASNIKI}

2.1.1 Dolgi naglašeni samoglasniki

2.1.1.1 Dolgi samoglasniki lahko nastopajo le pod naglasom, in sicer v vseh položajih.

2.1.1.2 Dolga /i:/ in /u:/ sta se povsod, razen v določenem glasovnem okolju, skrajšala ter tako prešla $\mathrm{v}$ sistem kratkega vokalizma. $i$ je dolg samo še pred $/ \mathrm{j} /, / \mathrm{r} /$ in včasih pred [u],$u$ pa pred $/ \mathrm{r} /$. Dolga sta tudi $\mathrm{v}$ mlajših sposojenkah.

2.1.1.3 Samoglasnika /è:/ in /ẹ:/ sta prosti različici, ki nista omejeni na določene položaje; tako imamo $m^{\prime} l e \dot{:} k$ ali $m^{\prime} l e: k$, 'zé:le ali 'ze:le.

2.1.1.4 Prav tako sta prosti različici samoglasnika /ö:/ in /ọ:/. Izgovarja se lahko 'gó:ba ali 'gọ:ba, me'só: ali me'sọ:. Samo /ọ:/ se govori v položaju pred [ü] ('čo:unn, 'o: luca, 'so:uzze).

2.1.1.5 /è:/ ni možen pred /j/ - v teh primerih imamo [e:] - ob'le:jčt, sta're:jša, žiúle:je. Z [e:] se večinoma prevzemajo sposojenke z naglašenim $e$-jevskim samoglasnikom ('pe:nzija). Podobno velja za [o:], ki se pojavlja v govoru nekoliko redkeje; najdemo ga v sposojenkah in knjižnih besedah ('o:pčina, pla'fo:n).

2.1.1.6 V redkih primerih (morda položajno in/ali ekspresivno) je /a:/ lahko tudi rahlo zaokrožen, zlasti za mehkonebniki (mož'gå:ne) in pred/za nosniki (do'må:, 'lå:n (prisl.), 'må:ma), vendar je tudi takrat pogostejša izgovorjava navadnega nizkega srednjega samoglasnika. Ni pa možen /å:/ pred istozložnim /j/ ali [u] - 'ba:jta, 'ja:jca, 'ša:jba; 'da:unč, kor'va:un, ro'ka:un.

2.1.2 Kratki naglašeni samoglasniki

2.1.2.1 Možni so v vseh besednih zlogih.

2.1.2.2 /i/ in (redkeje) /u/ imata včasih prosti različici [i] in [ụ] - gos'tịlna, Lọ̌́nịca, 'mịza, ž'vịna; 'sưša, 'tưdi.

2.1.2.3 /ə/ je mogoč v zadnjem ali edinem besednem zlogu ('porst, 'tort), pa tudi v nezadnjem ('čoru, 'dorve, 'gərl, u'məru). Najpogosteje je ob /r/; pred njim ima lahko prosto različico [a] ('parst, s'mart), v položaju ne ob /r/ pa prosto različico [e] ('dele, 'mende, 'nęc, 'tęk 'tako').

2.1.3 Kratki nenaglašeni samoglasniki

2.1.3.1 $/ 1 / 1 / \mathrm{m} /, / \mathrm{n} /$ in $/ \mathrm{n} /$ ne nastopajo ob samoglasnikih.

2.1.3.2 /o/ ima pred naglasom položajno različico [o] (kọ'lé:n, Ložnnịca, pọ'ča:s).

2.1.3.3 / / / je najpogostejši ob zvočnikih; $\mathrm{pred} / \mathrm{r} / \mathrm{ima}$ lahko prosto različico [a] (ar'ja:u, 'vé:tar), v drugih položajih pa /ę/ ('e:pkęt, 'nọ:tęr, spęt).

2.1.3.4 Predvsem v položaju za zobniki ima $/ \mathrm{m} /$ položajno različico [n] ('xo: $d n ̃ n$, 'o:sndeset).

2.1.3.5 Prosta različica fonema /i/, tj. [i], je zelo redka (ofj'ci:r, 'tudj).

\subsection{SOGLASNIKI}

2.2.1 Zvočniki

2.2.1.1 /v/ se govori pred sprednjimi in zadnjimi samoglasniki ( $\left.k^{\prime} r a: v a, n e^{\prime} v e \dot{s} s t a\right)$. 
Pred soglasniki in v izglasju ima /v/ različico [u] ( pred zvočniki pa se izgovarja kot /un/ ali /v/ (v'rå:telún'ra:te, v'rịe:mel un're:me).

2.2.1.2 /1/ je tudi pred zadnjimi samoglasniki srednji.

2.2.1.3 /1/ se v položaju za samoglasnikom in pred premorom premenjuje $\mathrm{z} / \mathrm{u} /$ ('da: $u$, rọ'di:un).

2.2.1.4 $n$ ima pred mehkonebniki /k, g, x/ položajno različico [y, y] ('a:ygl, 'firıki, 'lë:šnk).

2.2.2 Nezvočniki

2.2.2.1 V izglasju so mogoči samo nezveneči nezvočniki ('zo:p, s'tort 'med', $s^{\prime} n \dot{e}: k, \check{z} e^{\prime} l \dot{e}: s,{ }^{\prime} d \dot{l} e: \breve{s}_{)}$.

2.2.2.2 Po zvenečnosti se nezvočniki prilagajajo sledečemu nezvočniku ( $g$ 'ne:st 'gnezdo', g'rå:pt, 'o:pčina, otp'ré:t, s'la:tka, 'vitte 'vidite').

2.2.2.3 V položaju pred /n/ se /d/ lahko izgovarja kot [g] (g'na:r, dọ'po:gn, pọ'po:gñ).

2.2.2.4 V sklopu/td/se izgovarja le /d/ ali pa tudi ta odpade ('pé:(d)eset, 'šéeset, de've:(d)eset).

2.3 NAGLAS

2.3.1 Omejitev naglasnega mesta ni; dolgi in kratki naglašeni samoglasniki so možni v vseh besednih zlogih.

2.3.2 Nenaglašenih dolgih samoglasnikov govor ne pozna.

2.3.3 Možne so zložene in sestavljene besede z več naglasi ('ka:mno'ló:m, 'kọ:lno'kišta, 'nar'bo:l, 'ne:'za:konska, p'ra:'de:d, 'tum'xa:jt 'neumnost', 've:'ce.: 'vino'to: č).

2.3.4 Govor ne pozna končniškega naglasnega tipa; tako imamo 'čịe:bər 'čie:bra, s'tie:bor s'tie:bra.

\subsection{SAMOGLASNIKI}

3.1.1 Dolgi samoglasniki

i: $\quad \leftarrow$ stalno dolgi in staroakutirani $i$ v nezadnjem besednem zlogu (ter včasih dolgi in novoakutirani $e$ ) v položaju pred /r/ krom'pi:r, 'Mi:rko, o'bi:rat, 'pi:rje 'perje', se'ki:ra, šti:r;

$\leftarrow$ stalno dolgi in staroakutirani $i$ v nezadnjem besednem zlogu v položaju pred /j/ $(<i, n ́)$ - gospọ'di:ja, 'pi:jejo, sto'ji:jo, svina'ri:ja;

$\leftarrow$ stalno dolgi in staroakutirani $i$ v nezadnjem besednem zlogu v položaju pred/u/ - 'i:uje, na'pi:un, porọ'či:un, rọ'di:un, 'si:un, 'ži:uci;

$\leftarrow$ včasih izglasni $i-d^{\prime} n i$ : (R, T mn.), b'li:, 'mi:, no'či:, 'ti:, t'ri., 'vi:;

$\leftarrow$ redko /j/ + /e/ - 'i:ǔša 'jelša', 'i:st 'jesti', 'ki: 'kje';

$\leftarrow \mathrm{v}$ knjižnih besedah - 'i:gra, kita'ri:st, k'ni:žnca, ko'si:lo; 
$\leftarrow \mathrm{v}$ prevzetih besedah (večinoma $\mathrm{v}$ položaju pred $/ \mathrm{r} /$ ) adap'ti:rat, 'bi:rma, fab'ri:ka, for'di:rbat 'uničiti', ofj'ci:r, ošte'ri:ja, 'pi:r 'pivo', 'ri:xtat;

u: $\quad \leftarrow$ stalno dolgi in staroakutirani $u$ v nezadnjem besednem zlogu v položaju pred /r/ - 'Ju:rca, 'ku:r (R mn.), 'ku:rba, 'u:ra;

$\leftarrow$ izjemoma kratki $u-k^{\prime} r u: x$;

$\leftarrow$ včasih zgodaj podaljšani novoakutirani $o-' d u: b u$ (del. $-l$ ), 'ku:lk, 'u:na;

$\leftarrow$ redko o: $u-d o^{\prime} m u: / d a^{\prime} m u: ;$

$\leftarrow$ v knjižnih besedah - 'bu:nda, kul'tu:rno d'ru:štvo, ra'ču:n, $s^{\prime} l u: z ̌ b a$;

$\leftarrow$ v prevzetih besedah - 'fu:jtramo, 'ku:rzi (I mn.), 'pu:nca;

è:/ẹ: $\leftarrow$ stalno dolgi in staroakutirani $e v$ v nezadnjem besednem zlogu 'dè:tela, 'je:tre, 'pè:tek, pọk'le:knat, por'je:un, te'le:ta (R ed.), t're:sem, za'če: u;

$\leftarrow$ dolgi cirkumflektirani $e-$ 'le: $t$ 'led', pe'pe:u, dre'vé:sa (R ed.), s'me:t;

$\leftarrow$ novoakutirani $e$ v nezadnjem besednem zlogu - 'me:lem, 'ré:ku (del. -l), 'sé:dn, t'ré:k (vrstil. štev.), u'šé:sa (R ed.), 'zé:le, 'žé:nska;

$\leftarrow$ stalno dolgi in staroakutirani ě $\mathrm{v}$ nezadnjem besednem zlogu be'sé:da, b'rẹ:k, 'dè:l 'delo', ko'le::n, 'lè:t, 'me:snc, 'me:st, m'lè:k, s'ne:k;

$\leftarrow$ ě pred/r/-'cé:rku, x'čé:ra, 'mé:ra, 'vé:ra, zve'če::r, z'vé:r;

$\leftarrow$ naglašeni $\check{e} \mathrm{v}$ zadnjem besednem zlogu v položaju pred /un/ $g^{\prime} r e: u, s^{\prime} m \leftarrow: \underline{u}, z^{\prime} r e: u ;$

$\leftarrow$ izjemoma dolgi cirkumflektirani ə $\mathrm{v}$ nezadnjem besednem zlo$\mathrm{gu}-$ 've:s;

$\leftarrow$ redko iz/j/ + /e/ - 'kè: 'kje', lu'dè:, 'é:rbas 'jerbas';

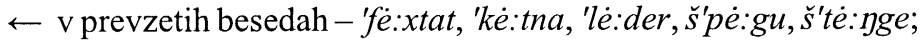

$\dot{\mathbf{o}}: / \mathbf{0}: \leftarrow$ stalno dolgi in staroakutirani $Q-{ }^{\prime} b o: b n$, , 'go $: b a, k^{\prime} r \dot{o}: k,{ }^{\prime} m \dot{o}: \breve{s} ;$

$\leftarrow$ dolgi cirkumflektirani $o-{ }^{\prime} b o: k / ' b o: x$, gos'po:t, me'só:, 'no: 'vo:js;

$\leftarrow$ novoakutirani $o$ v nezadnjem besednem zlogu - 'bo:tra, 'dó:bər, 'xo:dn, 'mo:kar, 'no:sn, 'ọ:le, 'ọ:sn, p'ró:sn, ško:rja, 'vó:la, 'vo:zn;

$\leftarrow$ stalno dolgi ter staroakutirani $f \mathrm{v}$ vseh besednih zlogih skupaj z [u] - 'čo:unn, 'dọ:unk (prid.), 'do:ưz̆n, 'so:uzze, 'vo:unna, 'žo:unna;

$\leftarrow \mathrm{v}$ posameznih primerih dolgi 1 - 'so:nce, 'so:nčnca;

$\leftarrow o$, ki je prišel pod naglas po mlajšem naglasnem umiku 'gó:senca;

$\leftarrow o$ različnega izvora v položaju pred istozložnim $[u](<\underline{u}, f)-$

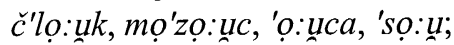

$\leftarrow$ naglašeni $a$ v zadnjem besednem zlogu v položaju pred isto-

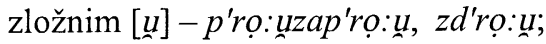


$\leftarrow$ naglašeni a v zadnjem besednem zlogu v položaju pred $[u]$ 'so: ư;

$\leftarrow$ v prevzetih besedah - f'ró:štik, 'ko:ln, 'lo:dn 'trgovina', 'šo:štar, št'ro:zuk;

ie: $\quad \leftarrow e$, ki je prišel pod naglas po umiku naglasa s končnega kratkega zloga - 'čie:l, 'nie:sla, 'tịe:ta, 'žie:na;

$\leftarrow \check{e}$, ki je prišel pod naglas po poznem umiku naglasa s končnega kratkega zloga - v'rịe:me, žriñe:l 'žrelo';

$\leftarrow \partial$, ki je prišel pod naglas po poznem umiku naglasa s končnega kratkega zloga - 'čie:bor, 'die:ska, 'mie:gla, 'pie:ku (sam.), 'tie:mn;

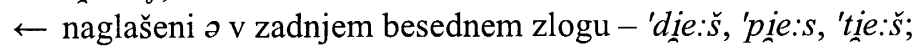

$\leftarrow$ v posameznih primerih novoakutirani ə - 'gie:ne 'gane';

$\leftarrow$ naglašeni $e, \check{e}, e \mathrm{v}$ zadnjem besednem zlogu - 'dine:t 'ded', 'nie:st, p'lie:st, 'rie:p, 'vie:č;

$\leftarrow$ včasih stalno dolgi in staroakutirani $\underset{\mathrm{v}}{\mathrm{v} \text { nezadnjem besednem }}$ zlogu - g'rie:da, 'mie:xek, 'pie:ta;

$\leftarrow e$, ki je prišel pod naglas po mlajšem naglasnem umiku 'bie:zguka;

$\leftarrow$ v prevzetih besedah - c'vie:k, š'tie:pix;

uo: $\leftarrow o$, ki je prišel pod naglas po umiku naglasa s končnega kratkega zloga - 'guno:ra, 'kuno:tu, 'nuo:ga, 'nuno:su, 'uo:sa, 'runo:jen, s'ruo:ka, 'uo: $d a$;

$\leftarrow$ naglašena $o, Q$ v zadnjem besednem zlogu - 'kuno:j, 'kuno:š/'kăs, k'ruo:p, 'puo:t 'pod', st'ruo:k, š'kuo:f;

$\leftarrow$ v posameznih primerih - 'muo:ški, 'muo:tn, 'ruo:ka;

$\leftarrow$ o po mlajšem naglasnem umiku - 'uno:trok/'vatrọk, 'puno:plat;

$\leftarrow$ o pod terciarnim naglasom - 'zuo: bi;

$\leftarrow$ v prevzetih besedah - $k^{\prime} n u n o: f l k^{\prime} n o f ;$

[e:] $\leftarrow$ /ẹ:/è:/ in /ie:/ različnega izvora v položaju pred /j/ - 'be:jš (vel.), 'me:jat, ọb'le:jčt, o'že:jen, 'pe:jmo (vel.), s'le:jčt, 've:ja, un'le:jčt 'vleči', žiúle:je;

$\leftarrow$ naglašeni $\check{e}, e, e$ v zadnjem besednem zlogu, večinoma v položaju ob zvočniku - d're:k, x'me:u, x're:n, k'me:t, 'ne:st;

$\leftarrow / a /$ in redkeje /a:/ različnega izvora $\mathrm{v}$ položaju pred istozložnim /j/ - 'de:j (vel.), d've:jst, 'ke:j (nedol. zaim.), 'me:jxn (I ed., mn.), 'ne:j, 'se:j, 'te:j 'tja', uk're:j 'vstran', (z)'de:j;

$\leftarrow$ včasih $e$ po poznem umiku naglasa s končnega kratkega zloga - je:zik, 'je:čmen;

$\leftarrow$ v posameznih primerih novoakutirani ə - 've:šk 'vaški';

$\leftarrow$ v novejših sposojenkah - fri'ze:r, inži'ne:r, mo'de:rno, 'pe:nzi$j a$;

[o:] $\leftarrow$ v novejših sposojenkah in knjižnih besedah - 'go:laš, 'lo:gor, 'o:pčina, pla'fo:n, st'ro:ji (I mn.), ze'lo:;

a:/å: $\leftarrow$ stalno dolgi in staroakutirani $a$ v nezadnjem besednem zlogu 
- 'a:pn, d'va:/d'vå:, g'ra:t, ko'va: ̌, k'ra:l, k'ra:valk'rå:va, 'ma:j, 'ma:t/'må:t, p'ra:x, t'ra:valt'rå:va, úra:t/u'rå:t;

$\leftarrow$ dolgi cirkumflektirani $ə$ in novoakutirani $ə \mathrm{v}$ nezadnjem besednem zlogu - 'ča:st, 'da:n, 'la:n, 'la:̌̌, 'ma:x, 'ma:šal'må:ša, 'sa:je 'sanje';

$\leftarrow a$ po premiku naglasa $\mathrm{z}$ zadnjega naglašenega zloga proti začetku besede - p'ra:xa (R ed.), úl'ra:ta (R ed.), st'ra:xa, 'ta:k (prid.);

$\leftarrow$ v prevzetih besedah - 'a:xtat, 'fa:jn, 'fa:rbat, 'må:ntl, šla:tat, 'ža:jfa;

3.1.2 Kratki naglašeni samoglasniki

i $\quad \leftarrow$ stalno dolgi in staroakutirani $i$ v nezadnjem besednem zlogu b'rije 'brinje', 'xišal'xjiša, ko'sit, 'lipal'lijpa, 'list, 'riba, 'sin, s'vija, ž'vina/ž'vina;

$\leftarrow$ kratki naglašeni $i$ v zadnjem besednem zlogu - 'miš, 'nit, 'rit, 'sit;

$\leftarrow$ naglašeni $i$ v izglasju $-b^{\prime} l i, s^{\prime} p i, \check{s}^{\prime} l i$;

$\leftarrow i$ pred istozložnim /ú/ - 'biưsí, 'diuji, 'siunka, 'žiuččn;

$\leftarrow i$ po mlajšem naglasnem umiku, lahko tudi po naglasni analogiji - 'pisanka, 'šivanka; $k^{\prime} l i c a l a$, 'pisala;

$\leftarrow \mathrm{v}$ prevzetih besedah - 'cigu, 'firtux, f'rišn, ma'šina, pe'cikl, 'piskor, 'sixt;

$\mathbf{u} \quad \leftarrow$ stalno dolgi in staroakutirani $u$ v nezadnjem besednem zlogu - 'buku, 'južna, k'luč, k'ruxa (R ed.), 'kura, 'lubje, 'lučl'luč, 'lupm, 'muxa, p'luče;

$\leftarrow$ naglašeni $u$ v zadnjem besednem zlogu - 'čut, 'juk, 'kup, o'but, $s^{\prime} k u p, ' t u$;

$\leftarrow-u t-$ 'ču 'slišal', na'su, o’'bu, se'zu;

$\leftarrow \mathrm{v}$ posameznih besedah po naglasni analogiji - 'sux (< suhó), 'pust (< pustó);

$\leftarrow$ v prevzetih besedah $-b^{\prime} l u z a$, 'cukər, 'nucat, $(s)$ 'pucat, 'šuxi;

e $\leftarrow$ v posameznih primerih umično naglašeni $e$ in $ə$ ter novoakutirani o- 'pečka, 'tenek, u'sexne 'usahne', ž'rebe;

$\leftarrow i:-s$ 'vene 'prašiček', 'peše 'pišče', 'jet 'iti';

$\leftarrow$ izjemoma istozložni naglašeni /a:/ + /ú $/-m^{\prime}$ reula;

$\leftarrow$ kratki in dolgi o po preglasu - p'reč, 'vejska, 'vejst 'voziti';

$\leftarrow \mathrm{v}$ prevzetih besedah - beš'tek, f'rej, par'cela, 'penzl, p'remza, 'reklc, 'tepix;

o $\quad \leftarrow$ včasih namesto $o: / o$ : in $\underline{n} o$ : različnega izvora - 'mogu, ni'kol, 'tojk 'toliko';

$\leftarrow$ v prevzetih besedah $-b^{\prime}$ lont, ffotor;

a/a $\leftarrow$ naglašeni $a$ v zadnjem besednem zlogu $-b^{\prime}$ 'rat, 'gat 'gad', s'tar, s'kaf ‘škaf'; zaimki: por 'nam/'nam, 'ngs, 'naš, 'tam/'tam, 'vam;

$\leftarrow$ v posameznih primerih dolgega $a-d ə r$ 'gač, 'kakršn, 'narta'lé:pš, $z^{\prime} \mathrm{ram}$; 
$\leftarrow o$, ki je prišel pod naglas po umiku naglasa s končnega kratkega, redkeje dolgega cirkumflektiranega zloga - 'kazuc, 'vatrọ;

$\leftarrow$ redko v prevzetih besedah $-g^{\prime} l a \check{s}, g^{\prime} l a z ̌ u n a ;$

ә [a] [e] $\leftarrow r$ : in $r$ skupaj z /r/ - 'boru, c'voru, če'tortek, 'čru, 'dorve, 'morzla, 'porse, 'porst, 'ərš, s'mərt, te'pəru, 'tərta, u'məru, 'žəru;

$\leftarrow$ različni reducirani samoglasniki, ki so prišli pod naglas po umiku naglasa s končnega kratkega zloga - 'cogan, 'dolel'dele 'sedaj', 'monde, 'poršu, 'soršen, 'šrek 'širok', 'vasek 'visok';

$\leftarrow$ včasih kratki naglašeni $e, \check{e}, a$ v zadnjem besednem zlogu 'von (prisl.); 'jos/'jes, 'nos, s'tor, 'tok/'tek 'tako', 'tom, 'tot (kaz. zaim.);

$\leftarrow$ redko kratka naglašena $i$ in $u-$ 'nəčl'něc, 'tole 'tule';

$\leftarrow$ redko dolgi naglašeni $e-z^{\prime} m e r i$;

\subsubsection{Nenaglašeni samoglasniki}

i $\leftarrow$ prednaglasni (kadar se ne reducira), ponaglasni in izglasni $i-$ i'mé:, ti'ši, 'zi'då:r; 'je:zik, ob 'uo:smix, z 'jim; b'ra:ti (I mn.), ž'ga:nki;

$\leftarrow \mathrm{v} \mathrm{M}$ mn., dv. in $\mathrm{O}$ mn., dv. sam. ž. sp. v končnicah -ax in -ami po analogiji - por k'ra:vix, z be'sé:dim;

$\leftarrow \mathrm{v}$ D mn., dv. sam. sr. in m. sp. v končnici -om po analogiji b'ra:tim, te'le:tim;

$\leftarrow$ izglasni $-a j \mathrm{v}$ velelniku glagolov na -ati, -am in prislovih 'de:li, pos'luši; 'komi, 'ne:ki, s'po:di, s'kupi, 'te:di 'tedaj', 'tuki, un'če:ri;

$\leftarrow$ v O ed. ž. sp. iz -oj-iz 'na: ̌̌i fa'miliji;

$\leftarrow$ včasih izglasni -ji- 'ka:či 'kačji', 'la:ži, 'o:ži, 'pe:jsi 'pasji', 'vè: $\check{i}$;

$\mathbf{u} \quad \leftarrow$ prednaglasni, ponaglasni in izglasni $u$ (v D, M ed. m. sp.) ču'då:k, xu'dič, lu'pina, u'še:se; t'ré:bux; b'rå:tu, 'kuo:ju, 'la:su;

$\leftarrow o$ po sporadičnem ukanju v vzglasju ter predvsem za ustničniki in mehkonebniki - ku 'ko', 'lè:tus, ust'rišt 'ostriči', uže'nila 'omožila', pu'ra:bmo 'porabimo';

$\leftarrow$ izglasni -ił, -ěł, -et, -oł in -at - 'cigu, 'die:bu (prid.), 'xuno:du, 'je:sku 'iskal', 'ne:su, 'nuo:su, 'uo:su/'vosu, 'poršu, 'uču, 'vidu, 'vorgu, z'gubu, 'živu;

$\leftarrow$ izglasni -ev-b'ré:sku, b'ritu, p'litu (prid.), 'rịe:tku; 'kuno:ju (R mn.);

$\leftarrow$ izglasni -ov-k'me:tu, 'žé:ninu (R mn.); sm'ré:ku (prid.);

$\leftarrow$ včasih izglasni -vo-k'ladu/k'la:du, po'sé:stu;

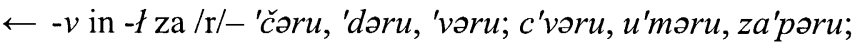

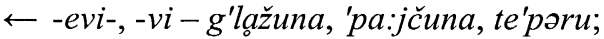

e $\quad$ prednaglasni in ponaglasni $\check{e}-d e^{\prime} l a: u c i, d r e^{\prime} v \dot{o}:, l e ' s \dot{e}: n$, res'nica, se'de:t, te'lo:; 'uno:rex, 'só:set, 'videt;

$\leftarrow$ prednaglasni, ponaglasni in izglasni $e-b e$ 'se:da, te'lé:ti, ze'lie:n; 'nịe:sem; 'mo:rje, 'po:le, 'rịe:če, 'tịe:če; 
$\leftarrow$ prednaglasni, ponaglasni in izglasni e -kle'či,pe'tina; 'på:met; 'tie:le, 'žịe:ne (R ed./I mn. ž. sp.);

$\leftarrow$ včasih prednaglasni in ponaglasni $a$ ob zvočniku /r/ -Ko'čè:verji, ner'dil; kọ'lọ:unret, mreư'liše, res'širu (del. -l);

$\leftarrow \mathrm{v}$ priponi -ek $(<-\jmath k) \mathrm{v}$ položaju ob nezvočnikih - 'pe:sek, 'pe:tek;

$\leftarrow$ redko nenaglašeni a za $d-d e$ (vez.), 'monde 'menda', se've:de;

$\leftarrow$ naglašeni $e$ po umiku naglasa s končnega dolgega zloga - 'sorce;

$\leftarrow$ redko prednaglasni $i-d e^{\prime} x u r, s v e ' j a ̊: k$;

o $\leftarrow$ ponaglasna in izglasna $o$ in $Q-$ ja:goda, 'puo:tok, 'žije:lot; 'Ma:rko, k'rå:vo, 'lipo, 'runo:ko; v glagolskih priponah -mo, -jo - 'bo:jo, 'kupmo, 'me:jamo, 'mo:rjo, nar'dijo, 've:jo, ž'vimo;

[o] $\leftarrow$ prednaglasna $o$ in $Q-g l o{ }^{\prime} b u n o: k, k o^{\prime} l \dot{e}: n, m o^{\prime} g \dot{o}: \check{c}, o^{\prime} c ̌ i ;$

a $\leftarrow$ prednaglasni, ponaglasni in izglasni $a \mathrm{v}$ I ed. ž. sp. - ma'line, nar'dil; 'dè:lat, 'så:tan, 'žå:gat; g'lå:va, g'ruška, k'rå:va;

$\leftarrow$ nenaglašena $o$ in $e$ v redkih primerih akanja - da'mu, 've:varca; v nikalnici ne - na 'bo:m, na 'bo: ś'lo, na 'vé:m;

$\leftarrow o$ v O ed. sam. m. in sr. sp. $-z$ b'ra:tam, $s$ 'kuo:jam, $z$ 'vo:jzam;

$\leftarrow$ v nedoločniški glagolski priponi -na--pok'le:knat, s'po:unnat, unz'dignat;

ə $\leftarrow$ nenaglašeni o pred $r$ - 'čịe:bər, 'do:bər, 'je:tor (R mn.);

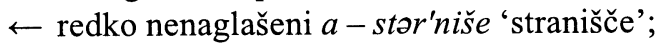

$\leftarrow$ izjemoma nenaglašeni $e-o n ' m a: l$;

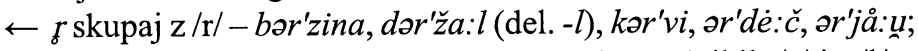

$\leftarrow \emptyset$ po onemitvi samoglasnikov $i, u, o$ ob zvočnikih $/ \mathrm{r} /$ in $/ 1 /$ 'jutər, pər'nè:su, štər'na:jst, dor'gač, ol'di (R, T ed.), 'xitor (prisl.);

\subsubsection{Zlogotvorni zvočniki}

I $\leftarrow l$ in $I$, če se je ob njiju reduciral samoglasnik - 'die:bl, 'gorl, 'kislca, 'mislt, por'jå:tlca, t'rupl; so m'la:tl, 'nie:sl, 'rie:kl, u'morl, 've: $d l$;

$\leftarrow$ v prevzetih besedah - kabl, 'la:jblc, 'må:ntl, 'ré:klc, 'tė:glc, ž'nå:bl;

m $\leftarrow m$, če se je ob njem reduciral samoglasnik (v primerih, ko ni prešel v ñ) - 'lupm, m'la:tm, 'mo:lm, 'pe:sm, 'pism;

$\leftarrow$ v prevzetih besedah - 'birmska, reuma'tizm;

n $\leftarrow n$ in $n$, če se je ob njiju reduciral samoglasnik - 'čie:sn, do'po:gn, g'lie:žn, 'je:dn, 'ke:dn, 'lè:šnk, 'mé:snc, no'bie:dn, ob'lå: čn (prisl.), pe'tie:ln, 'po:dn' 'tla', por'tisno(vel.), 'só:nčnca, sp'ré:dn, t'ra:ungk, 'zå:dn;

$\leftarrow$ pogosto iz -m (predvsem v položaju za zobniki) - 'no:sñ, 'o:sn, p'ro:sno, 'xo:dn, 'mo:rn, sn;

$\leftarrow$ v prevzetih besedah - 'ca:jtıge, 'firnki, 'žé:gn. 
3.2 SOGLASNIKI

Soglasniki so nastali iz enakih glasov kot $\mathrm{v}$ izhodiščnem sistemu (Logar 1981: 32) ali v prevzetih besedah, poleg tega pa še:

3.2.1 Zvočniki

$\mathbf{v} \leftarrow w$ pred sprednjimi in zadnjimi samoglasniki - 'vin 'vino', 'vo:la;

$\leftarrow$ včasih $w$ pred $r$ in $l-v^{\prime} r a ̊: t e, v^{\prime} r i ̣ e: m e, v^{\prime} r a: t, v^{\prime} l a: k$;

$\leftarrow$ v posameznih primerih kot proteza pred zadnjimi samoglasniki - 'vače, 'vejgi 'ogenj', 'vəsu 'osel', 'vatrọk;

u $\quad \leftarrow$ izglasni $l \mathrm{v}$ del. $-l \mathrm{~m}$. sp. ed. - 'da:u, 'pi:un, pər'jẹ:un, rọ'di:u, 'šọ:u, za'če:ư;

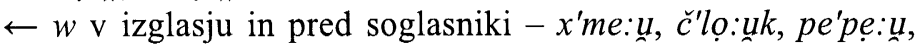
zd'ra:ujje, 'ži:uci;

$\leftarrow$ včasih $w$ pred $r$ in $l-u_{n}^{\prime} r a: t e, u^{\prime} r e: m e, u^{\prime} r a: t, u^{\prime} l e: j c ̌ t, u_{n}^{\prime} r \dot{o}: \check{c}$;

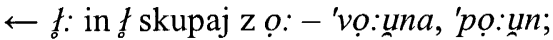

j $\leftarrow$ ń na začetku besede in v položaju med dvema samoglasnikoma - čre'pije, gospo'dija, x'ra:jen 'spravljeno', ka'me:je, 'ko:šja,je'go:u, ơ'že:jen, s'vija;

$\leftarrow n$ redko za soglasnikom - č'ré:šja, sadoun'jå:k;

$\leftarrow \mathrm{v}$ posameznih primerih kot prehodni (drugotni) $/ \mathrm{j} /$ - 'fu:jtrat, 'na:jgl, 'vejgi 'ogenj', 'o:jstor, 'pe:jsi 'pasji', 'ujzda, 'vo:js, 'vo:jzek;

$\leftarrow$ včasih kot proteza pred sprednjimi samoglasniki - 'je: $d n n^{\prime}$ 'eden', 'je:na 'ena', 'je:n 'eni', 'je:nket, 'je:mu (del. -l), 'je:sku (del. $-l)$, 'jet 'iti',

$\leftarrow$ v posameznih primerih mehčanja /g/v/j/ - 'ta:jga 'takega';

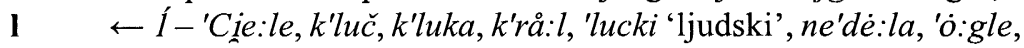
p'luče, 'pó:le, 'po:stla, s'té:la, 'vó:la, 'zé:le, 'zie:mla;

$\leftarrow$ primarne skupine $t l, d l-$ 'šil, 'vile,'vilce;

n $\leftarrow n ́$ v položaju za soglasnikom - k'niga, 'kuxna, 'lukna, og'niše, 'sukna, s'po:dna, s'vene, š'ko:rni;

$\leftarrow$ kot drugotni glas v prevzetih besedah - 'de:kna 'odeja', 'ke:tna 'veriga', š'te:nge 'stopnice', špan'cirat 'sprehajati se', 'zo:kni 'nogavice';

3.2.2 Nezvočniki

$\leftarrow r$ skupaj z ə-'gərl, 'səršen, 'torn, 'vorx.

$\mathbf{p} \quad \leftarrow b$ v nekaterih prevzetih besedah - p'lont, 'po:rma'šina;

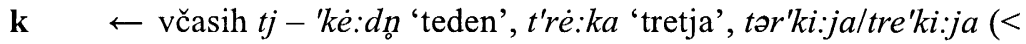
tretjinja);

$\leftarrow$ v skupini tn $-k^{\prime}$ nå:l 'tnalo';

g $\leftarrow$ v skupini $d n-g^{\prime} n a: r, d o^{\prime} p o: g n, p o p^{\prime} p o: g n ;$

$\mathbf{x} \leftarrow k$ pred $t$ ali $m-$ 'do:xtar, $x$ 'ma:l 'kmalu';

c $\leftarrow$ v posameznih primerih iz ts - de've:cto, 'so:cka 'soteska';

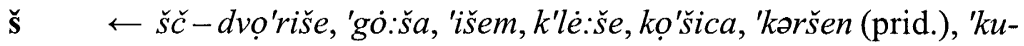
šar, 'lušt 'luščiti', 'ne:leš 'nalašč', og'niše, ti'ši; 
$\check{3} \leftarrow$ včasih $\check{c}$ v položaju pred zvenečim soglasnikom - do'ma: ̌̆ga, or'de: $\check{g} g$.

Zveneči nezvočniki $b, d, g, z, \check{z}$ so nastali tudi iz nezvenečih po asimilaciji na sledeče zveneče nezvočnike, nezveneči pa iz zvenečih $z$ asimilacijo na sledeče nezveneče nezvočnike in v izglasju; to velja tudi za nezvočnike, ki so prišli v omenjene položaje po onemitvi samoglasnikov.

\subsection{NAGLAS}

3.3.1 Naglasno mesto je kot $\mathrm{v}$ izhodiščnem sistemu, le da so zlogi, ki so bili tam pred naglašenimi kratkimi zadnjimi zlogi, naglašeni ('žie:na, 'kuno:sa, 'mie:gla). Naglasni umik s cirkumflektirane zadnje dolžine ni izvršen ( $k o^{\prime} l o \dot{o}:, m e^{\prime} s \dot{o}:, u^{\prime} x \dot{o}:$, zla'tó:). Oblike z umaknjenim naglasom so večinoma analogičnega izvora ('gó:senca, 'sərce, 'zəčneš).

3.3.2 Kolikost je kot $\mathrm{v}$ izhodiščnem sistemu $\mathrm{z}$ naslednjimi razlikami:

3.3.2.1 $i$ : in $u$ : sta skrajšana ('xiša, 'muxa).

3.3.2.2 Nekdanji kratki naglašeni samoglasniki v zadnjih ali edinih besednih zlogih so se večinoma podaljšali ('die:t 'ded', 'die:š, k'me:t, 'kuo:š, 'pie:s); izjema sta $i$ in $u$, ki sta večinoma ostala kratka ('miš).

3.3.2.3. Umično naglašeni samoglasniki so kratki ('cəgan).

\section{IZGUBA GLASOV}

\section{SAMOGLASNIKI}

- v prednaglasnih zlogih ob zvočnikih ( $p^{\prime} j a: c ̌ c a, s^{\prime} r \dot{0}: t a, \check{s}^{\prime} r u o: k a, \check{z}^{\prime} v i n a$, ž'va:t 'žival'); v predponi pri- se $i$ pred $r$ razvije v a (por'de:lki, pər'je: pər'nie:sl, pər'ja:tu);

- v ponaglasnih zaprtih zlogih ('južna, 'kuxna, p'ridga, t'ra:ungk); v priponah -ica, -ice ('gó:senca, 'pa:lca, 'vé:varca, 'vilce); pri tem lahko nastaneta tudi zlogotvorna l, ñ ('bo:Inca, 'le:tnca, 'só:nčnca, š'må:rñca, 'ustnca, ve'če:rnce); v glagolski priponi - $i$ - v sed. ed., mn. in dv. vseh oseb ('xo:dn, 'xo:dma, 'xo:tta, 'xo:dmo, 'xo:tte, 'xo:djo; 'vidno, 'vitte itd.); v nedoločniški priponi - $i$ - ('kupt, 'mislot, 'nuno:st); v del. -lžz. sp. ed. (c'villa, 'kupla, 'pustla, 'tọ:žla);

- v izglasju v D, M ed. večine sam. in prid. ž. sp. (po 'cẹ:st, por gos'tilnn, ư xme'la:rñ, na 'južn, na Lož'nịc, na 'mis); v D, M ed. os. zaim. za 1 . in 2. os. in povratnoos. zaim. (por 'mie: $n, k$ 'tie:p, $k$ 'sie:p); v O mn. sam. m., ž., sr. sp. (z be'sé:dim z z'ra:tim, ste'lé:tim); v prislovih in ostalih nepregibnih besedah ('duo:st, o'ko:l, pọ'le:t, úc'ca:s); v I ed. in mn. prid. m. sp. (te m'la:t 'mladi', ko'ruzn); v vrstil. štev. (te t're:k 'tretji'); v nedoločniku ('dé:lat, s'le:jčt 'sleči', ust'rišt 'ostriči'); v velelniški priponi -i- ('nie:smo, pie:čte, p'rim, uz'dignte); v končnici 3. os. mn. m. sp. del. -l ('be:jžal, 'dẹ:lal, f'ro:škal, obra'čo:val, dọ'bil, nar'dil, ž've:ll); v glagolski priponi $i$ - v 3. os. ed. sed. ('xo:t); 
$\mathbf{u}$

- redko v prednaglasnih zlogih (dor'gač, gol'fa:t, l'de:, s'tim 'pustim');

- redko v ponaglasnih zaprtih zlogih ('pa:ska 'pazduha');

- v izglasju v M ed. sam. m., sr. sp. (na 'kuo:nc, po 'mé:st, u 'sie:n); v R, $\mathrm{T}$ dv. os. zaim. za 1. in 2. os. ('na:j, 'va:j); v prislovih ( $x^{\prime} m a: l, n a$ 'vorx); - v prednaglasnih zlogih ob zvočnikih (člo: unk, s'ja:t 'sejati'); v pridevniški končnici -ěga in -ěmu ('e:nga, 'e:nmu, 'fa:jyga, 'na:žga, 'na:šmu, no'bie:nga, ob'le:jčenga, 'unga, pie:dga, 'todga); kot glagolska pripona v del. -l ('ve:dla, 've:dl, 'vidla, 'vid!);

- redko v prednaglasnih zlogih ( $\left.g^{\prime} n a: r, k u s^{\prime} v a: l a, n^{\prime}{ }^{\prime} d i t\right)$;

- v prednaglasnih zlogih - v glagolski medponi -ová- (kup'va:t, stan'va:t, izdel'va:t);

- v izglasju v I ed. sam. sr. sp. ('čine:l, 'mé:st, p'la:tñ, že'le:s); v prisl. ('čist, 'čudn, 'do:bor, 'xitor, 'lušn, ob'ln:

- v ponaglasnih zlogih v priponah -əc, -ək (ga'silc, $x^{\prime} l a: p c, x^{\prime} l e: p c$, 'kuo:nc, o'vink, 'pa:jk, 'tuo:rk, $z$ 'vo:nc, 'Ža:üc 'Žalec'); v nekaterih primerih za nezvočnikom pa je nenaglašeni o ohranjen kot $e$ (mar'tinček, 'pe:sek, 'pe:tek).

\section{SOGLASNIKI}

/j/ $(<i, n$ ) je onemel v vzglasju ali vzglasju pred /i/ ('i:uِša 'jelša', 'é:rbas 'jerbas', 'i:špri 'ješprenj', 'iva 'njiva').

Po redukciji samoglasnika $i$ za $v$ je začetni $v$ onemel v besedi 'nọ:grat.

V sklopu $p t$ - pride včasih tudi do izgovorne olajšave v $t$ - ('tič).

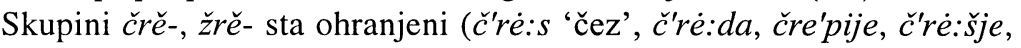
črre:ve, žr'rebe, ž'rebu/ž'rie:bu), v primeru 'čẹ:unli pa ne.

\section{OSTALI PRIMERI ONEMITEV:}

$\begin{array}{llll}\mathrm{b} & \leftarrow & \emptyset & - \text { one'mo:gu 'obnemogel', } \\ \mathrm{d} & \leftarrow & \emptyset & -\check{z} e^{\prime} l o: c, \\ \mathrm{~g} & \leftarrow & \emptyset & - \text { 'le:j(vel.), } \\ \mathrm{m} & \leftarrow & \emptyset & - \text { sed'na:jst, os'na:jst, } \\ \mathrm{t} & \leftarrow & \emptyset & - \text { 'ki:r<kateri (toda nek'ti:r), šes'na:jst, } \\ \mathrm{z} & \leftarrow & \emptyset & - \text { 'de:j 'zdaj'. }\end{array}$

Onemitve zaradi asimilacije:

$\begin{array}{llll}\mathrm{d}-\mathrm{m} & \leftarrow & \mathrm{n} & - \text { 'se: }: \text { deset, } \\ \mathrm{r}-\mathrm{r} & \leftarrow & \mathrm{r} & - \text { ma'šira, 'ma:trat, t'riket, z'ma:tran, } \\ \mathrm{td} & \leftarrow & \mathrm{d} / \emptyset & - \text { 'pe: }:(d) e s e t, \text { de've:(d)eset, 'śe:eset, } \\ \mathrm{vr} & \leftarrow & \mathrm{r} & - \text { 'tur 'tvor', } \\ \mathrm{zd}(<\mathrm{st}) & \leftarrow & \mathrm{s} / \mathrm{z} & - \text { 'pa:ska,'pé:tnd've: } j z g a .\end{array}$

\section{Prekozložna disimilacija:}

$\begin{array}{llll}\mathrm{l}-\mathrm{1} & \leftarrow & \mathrm{n}-\mathrm{l} & - \text { 'misnal 'mislili', } \\ \mathrm{m}-\mathrm{n} & \leftarrow & \mathrm{u}-\mathrm{n} & - \text { s'po:unnem, s'po:unnat, za'po:unnat, } \\ \mathrm{r}-\mathrm{r} & \leftarrow & \mathrm{j}-\mathrm{r} & - \text { 'fa:jmuštar, } \\ \mathrm{t}-\mathrm{t} & \leftarrow & \emptyset-\mathrm{t} & - \text { 'pu্o:plat. }\end{array}$


5.1 V besedilih se pojavljajo naslednje oznake: ${ }^{2}$

$\{I\}$ - izpust (nezapis) daljšega besedilnega odlomka,

$\{\mathrm{Sx}\}$ - smeh sodelujočih pri pripovedovanju,

$\{Z\}$ - zarek, tj. prekinitev stavčnega vzorca,

.. - krajši premor informatorja.

Pri zapisovanju napovednega spremnega stavka je pred dobesednim navedkom v premem govoru namesto dvopičja uporabljen pomišljaj. Premi govor je označen $z$ dvojnim srednjim narekovajem. $V$ besedilih se pojavljam tudi sama - kot stranska pripovedovalka oz. spraševalka. Moje besedilo se od ostalega loči po tem, da je pisano kurzivno.

\section{Vozili smo s konji}

'De:j pa ko-s 'mọ:gu, ư'ča:s si 'mọ:gu pa 'vejst is 'kuo:jam is 'cigunc, 'vẻ:te, 'tule, s 'kuo:jam na va'gọ:n u 'Ža:ưc. U'sa:k 'da:n si 'mọ:gu 'e:n va'gọ:n na'vọ:jst .. 'Mi smo ứča:s 'pəršl po 'tistix vese'licax - u pon'dè:lkix je b'lo 'nąr'bọ:l xu'dič, ko to ni b'lo 'ča:sa, ni b'lo 'tè:x vese'lic 'nəč, no'bie:ne so'bò:te, vese'lice, 'sa:m ọb ne'dè:lix. .. 'Puo:1 je pa 'ma:ma ư'ča:s - »'Ja:nko, « p'ra:u, »si že 'da:u 'kuo:jąm 'i:st?" Sn 'ré:ku - »Sn 'ja: 'da:u, če sñ g'lix 'pəršu da'mu. « Sñ 'da:u 'kuo:jim 'ji:st, po sñ 'da:uِ pa 'i:st, po sñ pa zas'pa:u. »'Jọ:zọs, « p'ra:u, »'pè:t je 'u:ra, 'pè:t je 'u:ra.« 'Ja: 'nəč, ọp 'še:stix si 'mọ:gu 'bit pa že 'guoo:r na, na 'ciguncix is 'kuo:jami pa z 'vọ:zam, 'jolte, si 'e:n va'gọ:n na'luo:žu do d'vẹ:x pọ́pọ:gn. 'Po sn pa ứča:s 'guxo:r na 'vọ:js 'sie:du, 'vé:te. Pro'me:ta pa ni b'lo 'tedi, 'a:utu, 'e:x, no'bie:yga.

(Povedal Janez Zagode (roj. 1925), Ložnica, 12. 9. 1999.)

\section{Vsi bi samo gledali, kaj se po svetu dogaja}

T'riče'tərt va'si je penzjọ'nistọ. Pa de 'kọkər 'zəčneš 'ke:j 'dè:lat, so kər 'jè:zn, kọ 'zəčneš rọpọ'tå:t. \{Sx\} A 'vè:š, ứsi 'ra:t po'čivajọ, u'si bi 'sa:m g'lè:dal, 'kuna: se po s'vè:t dọ'ga:ja, \{Sx\} pa 'fa:jno 'jè:dl pa 'pil, e'din 'tọ: je 'de:j. 'Nəč 'ni 've:č 'tịzga zag'na:åga, 'vè:š, pa 'nəč 'ni p'rọ:sto'vọ:lnga 'dè:la 'vie:č, 'nəč no'bie:dn 'nọ:če nọ'bịe:nim. Pa 'je:n d'rugim je ứ'sa:k 'fọ:ušs, de bi ứse 'kər .., \{Z\} 'sa:m da d'rugim 'ke:j 'cərkne. $\{I\}$ 'De:j 'tule 'ka:kix narkọ'ma:nọ še ne 'čutmo 'vəlk. 'Təm dọ 'Ža:ưca so že 'pəršs. $\{I\}$ 'Tək se žè po'ja:ulajo, 'nie:, 'ta:ke t'rume. Pa .. ne 'vè:m. U g'la:unim, 'nəč, no'bine:nga ne do'biš, če bi 'votu 'kej za $\{Z\}$ de bi ti 'kẹ:j pọ'ma:gu por 'dè:l. U'sa:k se 'kər zgọ'va:rja, de ma ọp'činsko pọt'pọ:ro pa 'ta:k. Ư'si 'ma:jo 'nè:ki g'nå:r, 'tək de jim 'ni t'rè:ba 'dè:lat.

(Povedal Štefan Lešnik (roj. 1949), Ložnica, 22. 2. 2001.)

2 Glede načina zaznamovanja gl. še Peter Weiss, Govori Zadrečke doline med Gornjim Gradom in Nazarjami: glasoslovje, oblikoslovje in skladnja: Magistrsko delo, Ljubljana 1990, 181 in Karmen Kenda-Jež, Cerkljansko narečje - teoretični model dialektološkega raziskovanja na zgledu besedišča in glasoslovja (rokopis), 2001. 


\section{Piva si ni mogel privoščiti vsak}

$X^{\prime} m e: l$ se je ứča:six $\{\mathrm{Z}\}$ 'ka:m se je tọ .. un A'me:riko se je iz'va:žu, 'ne:? H'me:ul.

X'me:ư se je iz'va:žu, se'vè:de. Pa 'se:j še z'de:j 'tudị, 'ne:, iz'va:ža. Sam z'de:j je 'tək s'la:ba tərgo'vina, de je tudi 'təm u .. 'tətix dər'ža:vix, 'ne:, un A'me:rik pa 'təm, kjè:r so ga 'mè:l ve'lik, je tudi ư'se s'lå:pšs, 'ne:. Sam so se z'de:j zdru'žujejo, 'ne:, de se zdru'žujejo, de bi jim b'lo 'bó:lš. Zarat 'tè:ga 'męnde, ko je z'de:j st'rəšñ ve'lik d'ruge pi'jå:če, 'vè:te, 'ja:, st'rəšn ve'lik d'ruge pi'jå:če. P'rej pa, p'rej pa 'ni b'lo 'tətix pi'ja:č 'tò:lk, 'ne:. 'Ki:r je 'ja:buček 'jemu do'må:, de je 'ja:pke sp'rè:šu, 'ne:, pa 'ki:r so 'mè:1 vi'nọ:grate, de sọ, de sọ 'mè:l 'vin pa 'tọ. 'tọ je b'lo, de bi pa 'tạ 'təte, 'tatle .. 'No, 'pivo je že tut 'biu, sam 'tọ si ga 'ni 'mọgu un'sa:k pər'uọ:št, 'ne:. Tọ so 'mè:l po gos'tilnix 'tu pa 'tam, pa za $\{Z\}$ 'tək za 'rè:tke pri'mẹ:re. Də'gəč pa k'me:ti 'tọ .. 'niso 'mè:1 g'na:rij, de bi xo'dil 'pit u gos'tilno. 'Ni b'lo g'na:rij.

(Povedala Ana Lešnik (roj. 1915), Ložnica, 22. 2. 2001.)

\section{Literatura}

JAKOP, Tjaša, Oblikoslovje govora Ložnice pri Žalcu: Magistrsko delo, Ljubljana 2001, 197 str. + pril.

LOGAR, Tine, Izhodiščni splošnoslovenski fonološki sistem, Fonološki opisi srpskohrvatskih/hrvatskosrpskih, slovenačkih i makedonskih govora obuhvaćenih opšteslovenskim lingvističkim atlasom, Akademija nauka i umjetnosti Bosne i Hercegovine, Sarajevo 1981 (Posebna izdanja LV, Odjeljenje društvenih nauka 9), str. 29-33.

KENDA-JEŽ, Karmen, Fonološki opis govora kraja Cerkno (OLA 6, SLA 166), Jezikoslovni zapiski 5, Inštitut za slovenski jezik Frana Ramovša ZRC SAZU, Ljubljana 1999, str. 201-234.

ŠKOFIC, Jožica, Fonološki opis kraja Lom pod Storžičem (SLA 204), Jezikoslovni zapiski 6, Inštitut za slovenski jezik Frana Ramovša ZRC SAZU, Ljubljana 2000, str. 141-153.

\section{Phonological Description of the Local Speech of Ložnica pri Žalcu (SLA 324) \\ Summary}

The local speech of Ložnica pri Žalcu belongs to the dialect of the Middle Savinja Valley. For the time being, the quantitative opposition is still preserved: the vowels can be either long or short (the long ones can only be stressed, whereas the short ones may be stressed or not), but because the short stressed vowels lengthen in the last or the only syllable ('kuo:š) - and the long ones shorten ('miza) - the quantity of the vowels no longer tends to be relevant. Another typical feature is that the short 
stressed vowels (especially $\mathrm{i}$ and $\mathrm{u}$ ) can be found not only in the last or the only syllable, which is typical of the standard language and central dialects, but in other syllables as well. Besides the general Slovenian stress-shifts this speech also underwent the shift-back to the pre-stress vowels e and o ('kuo:sa, 'sie:stra), and to the pre-stress schwa ('mie:gla).

The present-day dialect of the Savinja Valley results from contacts between the Gorenjsko and the Stajersko bases and is a relatively new conglomerate formation. While the Štajersko features show on the level of prosody (no tonemic stress), the Gorenjsko features appear mostly on the level of phonology, e.g. in the development of midvowels (there are equal narrow reflexes, i.e. è:/ẹ: and ò:/o:, for all ProtoSlavic long stressed vowels of the e and o types). It is one of the northeasternmost speeches with an a vocalization of $\overline{\mathrm{a}}$ and $\grave{\mathrm{\partial}}$-. The system of long vowels is monophthongal-diphthongal and consists of 7 phonemes: i:, è:/ẹ:, ie:, a:/å:, uno:, ò:/ $\mathrm{o}$ :, u., and the two systems of short vowels have 6 phonemes each (the stressed $\mathrm{i}, \mathrm{e}$, $\mathrm{a}, \mathrm{o}, \mathrm{u}$ and $\mathrm{\partial}$, and the unstressed $\mathrm{i}, \mathrm{e}, \mathrm{a}, \mathrm{o}, \mathrm{u}$ and $\mathrm{\partial}$ ). The long $\mathrm{i}$ and $\mathrm{u}$ have shifted into the short vowel system - with the exception of a few position-dependent instances. The vowel reduction is of a medium degree. Especially the unstressed high vowels i, è and a become silent when in combination with a sonorant and in word-final position. There is no umlaut after the functionally palatal consonants $\mathrm{j}(<\mathrm{i}, \mathrm{n}), 1(<\mathrm{i})$ and $\breve{\mathrm{c}}, \mathrm{z}$, $\breve{s}$ in this speech. The schwa sound that used to be stressed in word-final position (in the prefixes -əc and -ək) became silent in combination with the sonorants (ga'silc, 'kuo:nc, 'tuo:rk, 'Ža:ưc 'Žalec'), while in combination with other consonants it may be preserved as e ('pè:tek). Some of the unstressed vowels became silent in combination with the sonorants $/ \mathrm{l} /, / \mathrm{m} /, / \mathrm{n} /$ and $[\mathrm{n}]$ which resulted in the occurrence of the syllabic sonorants $/ 1 / 1 /, / \mathrm{m} /, / \mathrm{ng} /,[\mathrm{\eta}]$.

The consonant system reflects individual specific developments: 1 lost its palatal component and became 1 ('po:le), only the central articulation of 1 is used in this speech; in position after vowels ń has lost its nasal character and merged with the etymological $\mathrm{j}$ (s'vija), or, in combination with a consonant, it could have lost its palatal component and became n ('lukna); the groups črě-, žrě- are preserved in most cases (č'rè:šja, ž'rebe); the group šč assimilated into š (k'lè:še). The primary groups $\mathrm{tl}, \mathrm{dl}$ assimilated into 1 ('vilce), while the secondary groups $\mathrm{tl}, \mathrm{dl}$ are preserved in most cases ('buo:dla). The most frequent changes are: b/-p, d/-t, g/-k, z/-s, ž/-š, v/ -un. 